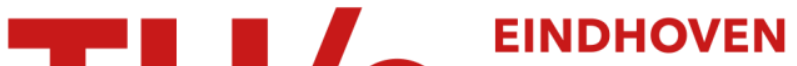 UNIVERSITY OF TECHNOLOGY
}

\section{Light emission of metal halide lamps under micro- and hypergravity conditions}

\section{Citation for published version (APA):}

Stoffels, W. W., Kemps, P. C. M., Beckers, J., Kroesen, G. M. W., \& Haverlag, M. (2005). Light emission of metal halide lamps under micro- and hypergravity conditions. Applied Physics Letters, 87(24), 241501-1/3. [241501]. https://doi.org/10.1063/1.2137989

DOI:

$10.1063 / 1.2137989$

Document status and date:

Published: 01/01/2005

\section{Document Version:}

Publisher's PDF, also known as Version of Record (includes final page, issue and volume numbers)

\section{Please check the document version of this publication:}

- A submitted manuscript is the version of the article upon submission and before peer-review. There can be important differences between the submitted version and the official published version of record. People interested in the research are advised to contact the author for the final version of the publication, or visit the $\mathrm{DOI}$ to the publisher's website.

- The final author version and the galley proof are versions of the publication after peer review.

- The final published version features the final layout of the paper including the volume, issue and page numbers.

Link to publication

\section{General rights}

Copyright and moral rights for the publications made accessible in the public portal are retained by the authors and/or other copyright owners and it is a condition of accessing publications that users recognise and abide by the legal requirements associated with these rights.

- Users may download and print one copy of any publication from the public portal for the purpose of private study or research.

- You may not further distribute the material or use it for any profit-making activity or commercial gain

- You may freely distribute the URL identifying the publication in the public portal.

If the publication is distributed under the terms of Article 25fa of the Dutch Copyright Act, indicated by the "Taverne" license above, please follow below link for the End User Agreement:

www.tue.nl/taverne

Take down policy

If you believe that this document breaches copyright please contact us at:

openaccess@tue.nl

providing details and we will investigate your claim. 


\title{
Light emission of metal halide lamps under micro- and hypergravity conditions
}

\author{
W. W. Stoffels, ${ }^{\text {a) }}$ P. C. M. Kemps, J. Beckers, and G. M. W. Kroesen \\ Eindhoven University of Technology, PO Box 513, 5600 MB Eindhoven, The Netherlands \\ M. Haverlag \\ Central Development Lighting, Philips Lighting, P.O. Box 80020, 5600 JM Eindhoven, The Netherlands
}

(Received 19 September 2005; accepted 26 October 2005; published online 5 December 2005)

\begin{abstract}
The wavelength-integrated light output from a metal halide discharge lamp is measured for gravity conditions varying from 0 to $1.8 \mathrm{~g}$ during parabolic flights. The results show that the changing gravity affects the convection flow in the lamp, which in turn changes the total light output. For vertically burning lamps, the sign and magnitude of the effect can be predicted using the demixing parameter: the ratio of typical diffusion to convection times. In horizontally burning lamps at $0 \mathrm{~g}$, the absence of convective mixing results in a reduced light emission. (C) 2005 American Institute of Physics. [DOI: 10.1063/1.2137989]
\end{abstract}

Metal halide discharge lamps are becoming increasingly more popular light sources due to their high efficiency and good color rendering properties. ${ }^{1}$ Nevertheless, the lamp exhibits several unwanted effects, which hinder a wider applicability and reduce its efficiency. A major problem is the radial and axial segregation of the radiating metal, which results in a lowered and nonhomogeneous emission from the lamp. ${ }^{2}$

A metal halide discharge lamp is essentially a highpressure (several to several hundreds bar) $\mathrm{Hg}$ arc discharge. ${ }^{3}$ In addition to the $\mathrm{Hg}$, which is the main species, a small amount of a metal halide salt is added. Examples of such salts are sodium iodide, thallium iodide, and various rareearth iodides. As these salts have a high melting point, they enter the plasma volume as a saturated vapor, its partial pressure dependent on the coldest spot in the lamp, which is between 1000 and $1500 \mathrm{~K}$. Towards the arc center, with a temperature of 5000-6000 K, the molecules dissociate and the metal atoms are excited and ionized. Excited rare-earth metal atoms and ions typically are extremely strong radiators in the visible, which explains the high efficiency of lamps containing these species.

Radial segregation in the lamp is caused by a lower diffusion speed of the larger molecule as compared to that of the smaller and lighter atom. Ionic diffusion can be even more enhanced by ambipolar diffusion. In order to reach a stationary state with an equal inward and outward flux of the metal in a molecular, atomic, or ionic state, a net gradient of the elemental partial pressure exists, with a minimum pressure in the center and a maximum along the colder walls. Note that this pressure gradient adds to the already lowered central density $n$, which is caused by the temperature gradient and described by the ideal gas law at constant pressure: $p=n k T$. As excited atoms and ions are the main radiation source, a strong radial segregation obviously has a negative effect on the lamp efficiency.

In order to fully understand the lamp behavior, convection also needs to be considered. The hot gas in the arc will tend to rise, whereas the colder gas along the walls will move downwards. The minority metal halide compounds in

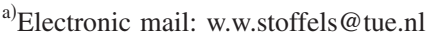

the lamp will simply follow the convection pattern of the dominant $\mathrm{Hg}$ gas. In a horizontally operating lamp this convection stream will counteract the radial segregation as it continuously "mixes" the cold and the hot regions of the gas. In addition, convection will lift the arc into its characteristic curved shape. Whereas convective mixing increases the lamp efficiency by reducing radial segregation, a curved arc close to the burner wall may result in a lower lamp emission.

In a vertically operating lamp the situation is slightly more complicated. The upstream convection is along the hot arc channel, with a lowered metal pressure and the downstream along the cold walls, with the higher metal pressures. The net effect is an increased down flow of the metal and a depletion of metal in the top part of the lamp. This so-called axial segregation not only results in lower lamp efficiency but also in a color separation within the lamp: the depleted top part emits a different light color than the lower metal-rich part. Figure 1 shows the convection-diffusion pattern in the lamp as well as pictures of a metal halide lamp. The effect of axial segregation on the lamp efficiency can be analyzed us-

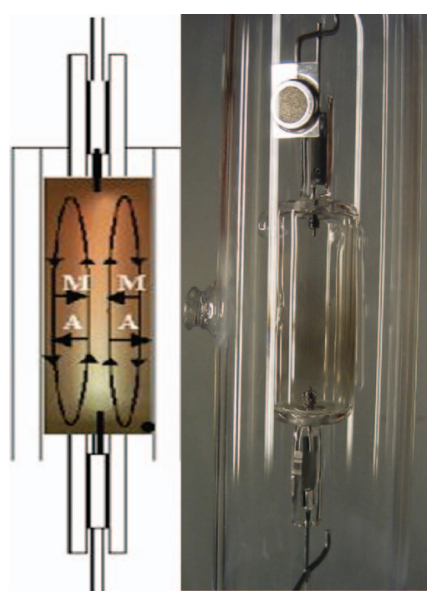

FIG. 1. (Color) Metal halide lamps. Left: A schematic view with a plasma arc developing between two electrodes. The arrows indicate the convection and diffusion processes of atoms and molecules. Right: a picture of a lamp with a quartz burner. The hot lamp burner is surrounded by a glass jacket, not shown in the left sketch, for safety reasons and to provide a controlled (vacuum or $\mathrm{N}_{2}$ ) environment to the burner itself. 


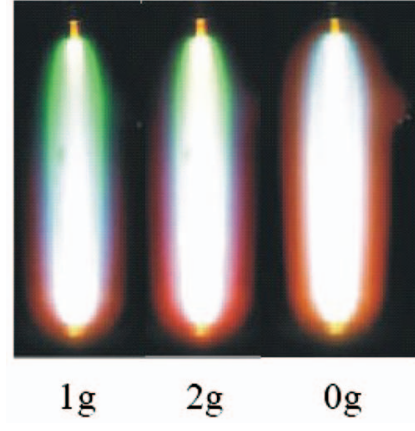

FIG. 2. (Color) Pictures of a vertically burning lamp in $1 \mathrm{~g}$ (left), $1.8 \mathrm{~g}$ (middle), and $0 \mathrm{~g}$ (right). The lamp, shown when off in Fig. 1, has a cylindrically shaped quartz wall with an inner diameter of $8 \mathrm{~mm}$ and electrode distance of $18 \mathrm{~mm}$ (aspect ratio 2.25). It is filled with $10 \mathrm{mg} \mathrm{Hg}$ and $\mathrm{DyI}_{3}$. The color separation and reduced light emission from the top part is clearly visible during the 1 and $2 \mathrm{~g}$ phases.

ing a demixing parameter $\Delta$, which is defined as the ratio of the effective radial diffusion time $\tau_{\text {dif }}$ to the typical convection time $\tau_{\text {con }}: \Delta=\tau_{\text {dif }} / \tau_{\text {con }}$. For $\Delta=0$, which means that the convection is unimportant, there is radial segregation but no axial segregation. For increasing $\Delta$, convection will cause axial segregation in addition to the radial segregation, lowering the lamp emission. Once $\Delta$ is larger than unity, convection will cause an increasingly better mixing of the species. Thus, the radial segregation decreases, which in turn decreases the axial segregation and increases the lamp emission. As $\Delta$ increases further to infinity, all segregation effects disappear, resulting in a lamp emission which surpasses the $\Delta=0$ value. The demixing parameter $\Delta$ depends on many lamp parameters, but it is clear that there must be a minimum in the lamp emission as a function of the convection in the lamp.

Here, we present measurements on the lamp as a function of convection speed. The experiments have been performed in an airplane during parabolic flights. In these flights a level-flying airplane pulls up strongly before switching off the engines and going into a parabolic free fall for about $20 \mathrm{~s}$. At the end of the parabola a second strong acceleration is used to prevent the plane from crashing. The result is that the experiment is subjected to a series of $1 \mathrm{~g}-1.8 \mathrm{~g}-0 \mathrm{~g}-1.8 \mathrm{~g}-1 \mathrm{~g}$ gravity conditions. During the hypergravity phases there is an increased convection, whereas there is no convection during the microgravity phase. In terms of the demixing parameter $\Delta$, this sequence implies that starting from its normal value, there is first an increase, then $\Delta=0$ during the $0 \mathrm{~g}$ phase; finally, there is again a high value before returning to normal.

In order to measure the total lamp emission, the lamps are placed in an integrating sphere, which collects and homogenizes the total light output of the lamp. This light is then detected by a photodiode supplied with a suitable optical filter, simulating human eye sensitivity. In addition to the integrating sphere, webcam pictures of the lamp have been made. Pictures of a lamp with $\Delta>1$ are shown in Fig. 2. The color separation is clearly visible, as the lower part of the lamp emits bright white light, whereas in the top part only a weak $\mathrm{Hg}$ emission is seen. The radial segregation in the hypergravity phase is significantly less than in the $1 \mathrm{~g}$ phase, as can be seen in Fig. 2. In the microgravity phase the light emission is homogeneous in the axial direction. As expected, the emission increases during the hypergravity phases. Also, Downloaded 24 Oct 2007 to 131.155.108.71. Redistribution subject

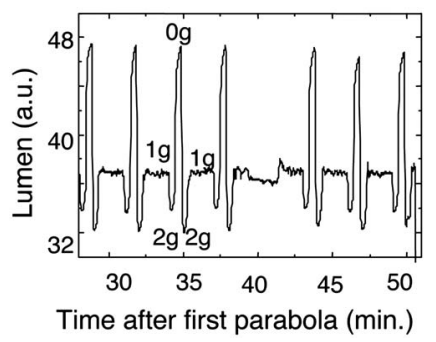

FIG. 3. Light emission of a vertically burning lamp as a function of time during several parabolas. The lamp has a cylindrically shaped polycrystalline alumina (PCA) wall with an inner diameter of $4 \mathrm{~mm}$ and electrode distance of $16 \mathrm{~mm}$ (aspect ratio 4). It is filled with $3.46 \mathrm{mg} \mathrm{Hg}$ and a $\mathrm{NaCe}$ salt mixture.

a clear decrease below the $1 \mathrm{~g}$ value can be seen at the start of the microgravity phase.

Figure 3 shows the integrated light emission of a long and thin lamp, operated in a vertical direction, as a function of time during several parabolas. The parabolic sequences are clearly identifiable and well reproducible. The microgravity phase shows an increased light emission, while the emission is reduced during the hypergravity phases. In this long and slender lamp, radial diffusion is expected to dominate over convection $\left(\tau_{\text {dif }}<\tau_{\text {con }}\right)$, so the demixing parameter $\Delta$ is smaller than 1 . This explains that an increased $\Delta$-as occurs during the hypergravity phase-results in an increased demixing and a lower light output, whereas the $0 \mathrm{~g}$ phase with $\Delta=0$ has a higher light output.

Finally, the integrated light output during several parabolas for a horizontally operating lamp is shown in Fig. 4. In this case there is only radial and no axial segregation. The light emission decreases under microgravity, as there is no convection to counteract the radial segregation. Furthermore, there is hardly an increase during the hypergravity phases before and after the $0 \mathrm{~g}$, which shows that the convection under normal operating conditions is sufficient for a good mixing of the metal species in the lamp. Note that convection will also lift the arc into its characteristic curved shape, and that emission is reduced if the arc comes close to the lamp wall. In long and thin lamps, as discussed before, this effect is dominant and results in a higher emission during $0 \mathrm{~g}$, where arc curving is suppressed.

In conclusion, we can say that the light output of a metal halide lamp strongly depends on the gravity conditions. This can be qualitatively understood as a balance between convection and diffusion of the radiating metal species in the lamp.

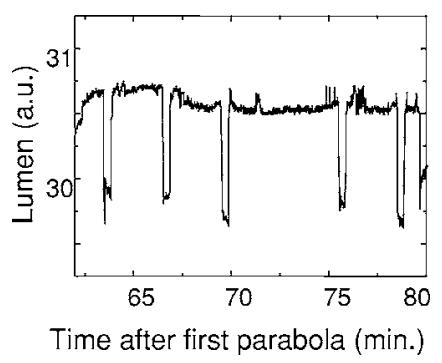

FIG. 4. Light emission of a horizontally burning lamp as a function of time during several parabolas. The lamp has a cylindrically shaped PCA wall with an inner diameter and electrode distance of $6 \mathrm{~mm}$ (aspect ratio 1). It is filled with $9 \mathrm{mg} \mathrm{Hg}$ and a NaTIDy salt mixture. During the normal and hypergravity phases light emission is equal; only during microgravity the light emission is reduced. 
In horizontally operating lamps convection will tend to mix the species, which improves the lamp efficiency. In vertically operating lamps the situation is described by the demixing parameter $\Delta$, where the light emission has a minimum for $\Delta=1$.

The authors wish to thank all participants in the ARGES project for their contributions, ESA and Novespace for supplying the parabolic flight, senter-novem, and the Ministries of Research and Education as well as Economic Affairs for their financial support.

${ }^{1}$ J. Phys. D edited by D. O. Wharmby, G. Zissis, and J. E. Lawler, Special issue on light sources 38, 2995-3333 (2005).

${ }^{2}$ E. Fisher, J. Appl. Phys. 47, 2954 (1976); H. P. Stormberg, ibid. 52, 3233 (1981).

${ }^{3}$ G. G. Lister, J. E. Lawler, W. P. Lapatovich, and V. A. Godyak, Rev. Mod. Phys. 76, 541 (2004). 